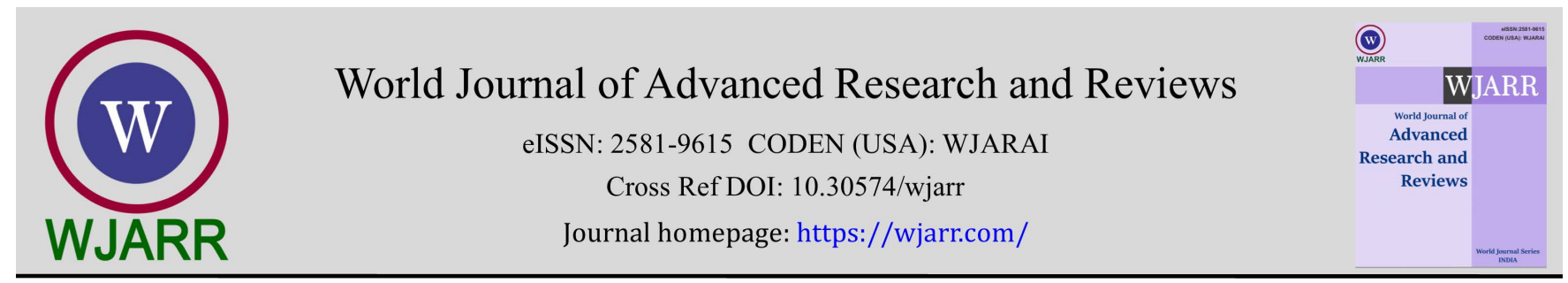

(RESEARCh ARTicle)

\title{
Analgesic radiation therapy for bone metastasis in Dakar
}

Kanta Ka ${ }^{1,}{ }^{*}$, Mamadou Moustapha Dieng 2, 4, Papa Macoumba Gaye 1,4, Boucar Ndong 1,4, Mahomed Ilyas Yessoufou 3, El hadj Amadou Sall 2, El hadj Aliou Balde 2, Ibrahima Thiam 2, Awa Sadikh Badiane ${ }^{2}$ and Touria Bouhafa $^{3}$

${ }^{1}$ National University Hospital Center of Dalal Jamm, Guédiawaye, Senegal.

2 Joliot Curie Institute of the University Hospital Center of Aristide Le Dantec, Dakar, Senegal.

${ }^{3}$ Radiotherapy Department of the Oncology Hospital of the University Hospital Center Hassan II, Fez, Morocco.

${ }^{4}$ Cheikh Anta Diop University, Dakar, Senegal.

World Journal of Advanced Research and Reviews, 2021, 11(03), 220-225

Publication history: Received on 13 August 2021; revised on 16 September 2021; accepted on 18 September 2021

Article DOI: https://doi.org/10.30574/wjarr.2021.11.3.0451

\begin{abstract}
Background: Three-dimensional conformal radiotherapy is a new tool in the Senegalese therapeutic arsenal. Symptomatic bone metastases affect the quality of life of patients. Analgesic radiotherapy is proposed to patients to relieve them.

Patients and methods: A prospective descriptive study was carried out on all patients with symptomatic bone metastasis. Hypo-fractionated radiotherapy was performed on the painful site. The visual analogue scale was used to assess pain before radiotherapy, 72 hours and one week after. Results: The sex ratio was 0.5 . The median age at diagnosis of symptomatic metastasis was 53 years. All patients received $8 \mathrm{~Gy}$ (Gray) in one session. A complete response was noted one week post radiotherapy.
\end{abstract}

Conclusion: Analgesic radiotherapy improves the quality of life of patients with symptomatic bone metastasis.

Keywords: Bone metastasis; Radiotherapy; Pain; Quality of life

\section{Introduction}

Bone metastasis occurs in approximately two-thirds of cancer patients. After the lung and liver, bone is the most common metastatic site [1]. Bone metastasis is an important cause of morbidity and impairs the quality of life of patients, particularly because of pain [1]-[3].

Analgesic radiotherapy is integrated into the management of bone pain in the same way as surgery and medical treatments following the multidisciplinary consultation meeting. It is effective with very few side effects [4], [5].

Previously poorly known in our work setting, practitioners are increasingly referring patients for analgesic radiotherapy.

We conducted a prospective study in our department to evaluate the effectiveness of analgesic radiotherapy.

\footnotetext{
${ }^{*}$ Corresponding author: Kanta Ka

National University Hospital Center of Dalal Jamm, Guédiawaye, Senegal. 


\section{Patients and methods}

\subsection{Patients}

All patients received in the department for one or more symptomatic bone metastasis regardless of the primary location.

\subsection{Non-inclusion criteria}

All patients with asymptomatic bone metastasis;

Symptomatic non-bone metastasis.

Primary bone cancers

\subsection{Type of study}

Single-centre prospective descriptive study of 06 months (July to December 2018).

\subsection{Location}

Radiotherapy department of the Dalal Jamm National University Hospital with two ELECKTA 10 MEV linear accelerators.

\subsection{Pain assessment, treatment and follow-up}

Pain assessment is done by visual analogue scale before and after radiotherapy [6].

All patients were consulted, simulated, bypassed and treated with hypo-fractionation in one session on the same day.

Patients were seen in consultation 72 hours after radiotherapy and one week afterwards a telephone consultation was made.

\subsection{Definition of response criteria}

The efficacy of radiotherapy on pain relief is defined according to Chow et al [7].

Table 1 Definition of response to palliative irradiation according to Chow et al

\begin{tabular}{|l|l|}
\hline Complete response & $\begin{array}{l}\text { Pain score }=0 \text { at the treated site Without concomitant increase in analgesic } \\
\text { consumption, which remained stable or decreased }\end{array}$ \\
\hline Partial response & $\begin{array}{l}\text { Reduction in pain score } \geq 2 \text { at the treated site without increase in analgesic } \\
\text { consumption or decrease in analgesic consumption } \geq 25 \% \text { without increase in } \\
\text { pain }\end{array}$ \\
\hline Progression & $\begin{array}{l}\text { Increase in pain score } \geq 2 \text { at the irradiated site with stable pain medication } \\
\text { consumption Or Increase } \geq 25 \% \text { in pain medication consumption with stable } \\
\text { pain score } \pm 1 \text { point }\end{array}$ \\
\hline $\begin{array}{l}\text { Undetermined } \\
\text { response }\end{array}$ & $\begin{array}{l}\text { Any response that does not meet the definition of a complete, partial or } \\
\text { progressive response }\end{array}$ \\
\hline
\end{tabular}

\subsection{Statistical analysis}

The Sphinx software was used to calculate the mean, median and the number of participants (number and percentage). 


\section{Results}

The characteristics of the patients are summarised in Table 2. Our radiotherapy department treated 298 patients of all stages over a period of six months. Of these patients, 19 were treated for symptomatic bone metastasis; that is, $06.38 \%$. Seven patients did not return for consultation because of the difficulty of travelling by ambulance. 12 patients were finally retained. Females predominated with 8 patients (66.7\%) out of 4 males (sex ratio: 0.5 ). The median age was 53 years with extremes of 37 and 83 years. Breast was the primary primary location with 6 cases (50\%) followed by prostate with 2 cases (16.7\%) and 1 case for endometrium, rectum, ankle and multiple myeloma. Ten (10) patients were under anti-cancer treatment; that is $83.3 \%$. The lumbar location was the most frequent with 05 cases, followed by the dorsal location with 04 cases and the dorsolumbar location with 03 cases. The average pain assessment according to the visual analogue scale was $09 / 10$. Nine patients had analgesic treatment prior to radiotherapy, i.e. $75 \%$ of patients without a complete response. Two patients had a partial response of short duration. All patients were seen in consultation, simulated, bypassed and set up for treatment on the same day. All patients received a single dose of $08 \mathrm{~Gy}$ of analgesic radiotherapy. Seventy-two hours after treatment, 07 patients had a partial response, 04 had no response and 01 had a total response. Four patients had a rebound effect after 72 hours of follow-up. One week after treatment, all patients had a complete response.

Table 2 Patient characteristics

\begin{tabular}{|l|l|c|}
\hline Patient characteristics & & Numbers N (\%) \\
\hline Age (years) & -40 & $2(16,6)$ \\
\hline & +40 & $10(83,3)$ \\
\hline Metastasis site & Dorsal & $4(33)$ \\
\hline & Lumbar & $5(42)$ \\
\hline & Dorso-lumbar & $3(25)$ \\
\hline Radiotherapy technique & 3D Conformational & 12 \\
\hline Dose (Gy) & 8 & 12 \\
\hline Analgesic after treatment & Yes & $9(75)$ \\
\hline & No & $3(25)$ \\
\hline Primary site & Breast & $6(50)$ \\
\hline & Prostate & $2(16,7)$ \\
\hline & Rectum, ankle, uterus, multiple myeloma & $1(33,3)$ \\
\hline Ongoing chemotherapy & & $10(83,3)$ \\
\hline
\end{tabular}

\section{Discussion}

The sex ratio in our study is 0.5 . Bone metastases occurred more in women than in men in most studies [3], [8]. The series by Spencer et al. found no difference between men and women [9]. The median age at diagnosis of symptomatic bone metastasis in our study was 53 years. This was in agreement with the literature with a median age ranging from 52 to 67 years [3], [8].

The most common primary cancer site was breast, followed by lung and prostate [3], [8]-[10]. Our study seems to confirm these results: breast (50\%), prostate (16.7\%). It should be noted that in the published clinical trials, breast (35$45 \%)$, prostate (10-35\%) and lung (10-35\%) are the best described sites; the others (radiation-resistant and haematological tumours) are often excluded or not specified.

The spine was the first location irradiated in many studies [11] [12].

The study by Le Fèvre $C$, et al. found a preferential location in the spine in 59\% of cases [1], [3]. Our study found an exclusively spinal location, preferentially lumbar. 
All our patients were evaluated according to the visual analogue scale (VAS) at the initial consultation. This evaluation showed a median VAS of 9/10. European studies do not find the same value, 6 and 7 respectively [3] [13]. This can be explained by the fact that the patient is managed in the same centre. In our work context, patients are often followed by several services in different locations, which means that the prescription of analgesics is not uniform.

$83.3 \%$ of our patients were on anticancer treatment (chemotherapy and/or hormonal therapy), in contrast to most studies of bone metastases [12], [14].

The Le Fèvre $\mathrm{C}$ et al. and Nielsen et al. studies found that $73 \%$ of patients were taking analgesics [3], [14]. It should be noted that in the Le Fèvre C, et al. study, $23 \%$ of patients were asymptomatic and $74 \%$ of them did not require analgesics [3].

Our study found the same proportion of patients taking analgesics, i.e. 75\%. This contrasts with the study by Kaasa et al [15].

All our patients were seen in consultation, simulated, bypassed and treated on the same day contrary to the French studies [1], [3]. Several fractionation schemes can be used for the irradiation of uncomplicated bone metastases. Our therapeutic standard is a dose of $8 \mathrm{~Gy}$ in one session by three-dimensional conformal radiotherapy. In the study by Le Fèvre et al. 2 patients were treated by stereotaxis and the rest by 3D conformal technique. Treatment regimens varied: 30 Gy in 10 fractions, 20 Gy in 5 fractions and 8 Gy in 1 fraction. 20\% of patients received treatment with 8 Gy in one session [3]. It should be noted that randomised studies and meta-analyses do not show any superiority between these treatment regimens in the management of uncomplicated bone metastases. Moreover, they show that the hypofractionated regimen was more commonly used by experienced radiotherapists [13], [16], [17], [14]. The study by Slotman et al. showed that the majority of patients preferred a one-day management [18].

Our study found a significant decrease in pain after treatment, i.e. VAS less than 3, in line with French studies [1], [3].

The rebound effect or "pain flare" is one of the acute complications of irradiation and corresponds to a paradoxical increase in pain at the irradiated site. It usually occurs after one to five days from the start of radiation and lasts for about three days. Its incidence is about $40 \%$ after three-dimensional treatment and may even reach more than $60 \%$ after stereotactic radiotherapy [19]-[23]. A rebound effect was found in 4 patients at 72 hours follow-up, controlled by corticosteroid therapy. In the study by Le Fèvre C et al, no rebound effect was observed [3].

Our study found a partial response in 58\% of patients at 72 hours of treatment and a total response at one week in all patients. The efficacy of three-dimensional radiotherapy is reported to be between one and four weeks depending on the study [1], [3]. Some studies found efficacy at least 3 weeks [9], [24], [25].

This study, although prospective, shows some limitations related to the evaluation of medical analgesic treatments. Indeed, the patients received several analgesic treatment regimens defying all prescription logic. They went from firsttier to third-tier analgesics or even from a synergistic, unproductive second- to third-tier combination. There were also breaks in the supply of third-tier analgesics. All these facts could constitute points for discussion.

\section{Conclusion}

Analgesic radiotherapy is effective and easy to implement. It must be better popularised to improve the pain control of our patients. The limitations related to the prescription of analgesic drugs would require in-depth training and a larger multicentre prospective study could help to adapt the management of symptomatic bone metastases in our patients.

\section{Compliance with ethical standards}

\section{Disclosure of conflict of interest}

No conflict of interest.

\section{Statement of informed consent}

Informed consent was obtained from all individual participants included in the study. 


\section{References}

[1] C Le Fèvre, D Antoni, A Thiéry, et G. Noël. «Radiothérapie des métastases osseuses : revue multi-approches de la littérature », Cancer/Radiothérapie. 2018; 22(8): 810-825.

[2] JC Faivre et al. «Radiothérapie conformationnelle des métastases osseuses vertébrales », Cancer/Radiothérapie. 2016; 20(6): 493-499.

[3] C Le Fèvre et al. " Radiothérapie des métastases osseuses en France: étude descriptive rétrospective monocentrique », Cancer/Radiothérapie. 2018; 22(2): 148-162.

[4] S Lutz et al. « Palliative radiation therapy for bone metastases: Update of an ASTRO Evidence-Based Guideline », Pract. Radiat. Oncol. 2017; 7(1): 4-12.

[5] S Lutz et al. " Palliative radiotherapy for bone metastases: an ASTRO evidence-based guideline », Int. J. Radiat. Oncol. Biol. Phys. 2011; 79(4): 965-976.

[6] Les échelles de la douleur -Adulte - Echelles d'auto évaluation | SFAP - site internet ». http://www.sfap.org/document/les-echelles-de-la-douleur-adulte-echelles-d-auto-evaluation (consulté le août 10, 2021).

[7] E Chow, K Harris, G Fan, M Tsao, WM Sze. « Palliative Radiotherapy Trials for Bone Metastases: A Systematic Review », J. Clin. Oncol. 2007; 25(11): 1423-1436.

[8] TJ Rick et al. « Radiotherapy Practice for Treatment of Bone Metastasis in Ethiopia », JCO Glob. Oncol. 2020; 6: 1422-1427.

[9] K Spencer, G Velikova, A Henry, P Westhoff, PT Hall, YM van der Linden. « Net Pain Relief After Palliative Radiation Therapy for Painful Bone Metastases: A Useful Measure to Reflect Response Duration? A Further Analysis of the Dutch Bone Metastasis Study », Int. J. Radiat. Oncol. Biol. Phys. 2019; 105(3): 559-566.

[10] T Saito, R Toya, N Oya. « Pain Response Rates After Conventional Radiation Therapy for Bone Metastases in Prospective Nonrandomized Studies: A Systematic Review », Pract. Radiat. Oncol. 2019; 9(2): 81-88.

[11] HS Smith, RL Barkin. « Painful boney metastases », Am. J. Ther. 2014; 21(2): 106-130.

[12] D Rades, SE Schild, JL Abrahm. « Treatment of painful bone metastases », Nat. Rev. Clin. Oncol. 2010; 7(4): 220-229.

[13] R Chow et al. « Efficacy of multiple fraction conventional radiation therapy for painful uncomplicated bone metastases: A systematic review », Radiother. Oncol. 2017; 122(3): 323-331.

[14] Randomized trial of single dose versus fractionated palliative radiotherapy of bone metastases - PubMed ». https://pubmed.ncbi.nlm.nih.gov/9681885/ (consulté le août 10, 2021).

[15] S Kaasa et al. « Prospective randomised multicenter trial on single fraction radiotherapy (8 Gy x 1) versus multiple fractions (3 Gy x 10) in the treatment of painful bone metastases », Radiother. Oncol. J. Eur. Soc. Ther. Radiol. Oncol. 2006; 79(3): 278-284.

[16] R McDonald, E Chow, H Lam, L Rowbottom, H Soliman. « International patterns of practice in radiotherapy for bone metastases: A review of the literature», J. Bone Oncol. 2014; 3(3-4): 96-102.

[17] T Saito, K Yamaguchi, R Toya, N Oya. « Single- Versus Multiple-Fraction Radiation Therapy for Painful Bone Metastases: A Systematic Review and Meta-analysis of Nonrandomized Studies », Adv. Radiat. Oncol. 2019; 4(4): 706-715.

[18] DE Spratt et al. « An integrated multidisciplinary algorithm for the management of spinal metastases: an International Spine Oncology Consortium report », Lancet Oncol. 2017; 18(12): e720-e730.

[19] A Lachgar, N Sahli, N Benjaafar. «Éxacerbation de la douleur après la radiothérapie externe antalgique : étude prospective de 41 cas », Cancer/Radiothérapie. 2017; 21(5): 373-376.

[20] A Hird et al. « Determining the Incidence of Pain Flare Following Palliative Radiotherapy for Symptomatic Bone Metastases: Results From Three Canadian Cancer Centers », Int. J. Radiat. Oncol. Biol. Phys. 2009; 75(1): $193-197$.

[21] «Pain flare in patients with bone metastases after palliative radiotherapy-a nested randomized control trial | SpringerLink » 2021. 
[22] «Incidence of pain flare following palliative radiotherapy for symptomatic bone metastases: multicenter prospective observational study | BMC Palliative Care | Full Text ».

[23] A Chiang et al. « Pain Flare Is a Common Adverse Event in Steroid-Naïve Patients After Spine Stereotactic Body Radiation Therapy: A Prospective Clinical Trial », Int. J. Radiat. Oncol. Biol. Phys. 2013; 86(4): 638-642.

[24] R McDonald et al. «Effect of Radiotherapy on Painful Bone Metastases: A Secondary Analysis of the NCIC Clinical Trials Group Symptom Control Trial SC.23 », JAMA Oncol. 2017; 3(7): 953-959.

[25] HJ McQuay, SL Collins, D Carroll, RA Moore. "Radiotherapy for the palliation of painful bone metastases », Cochrane Database Syst. Rev. 2000; 2: CD001793. 